\title{
PEMBELAJARAN DWIBAHASA DI SEKOLAH DASAR: PELAKSANAAN, KENDALA, DAN HARAPAN
}

\author{
Defina, Krishandini, Laksmi Arianti, Henny Krishnawati, \\ Hesti Sulistyowati \\ Intitut Pertanian Bogor \\ krishandini@yahoo.com
}

\begin{abstract}
Abstrak
Sekolah dasar (SD) di Indonesia, khususnya di Bogor, Jawa Barat, diberikan mata pelajaran pendidikan dua bahasa: Indonesia dan bahasa ibu atau daerah (bahasa Sunda). Akan tetapi, dari pengamatan sementara pengajaran dwibahasa menimbulkan berbagai kendala. Sehubungan dengan hal itu, tujuan penelitian ini adalah 1) mendeskripsikan proses pembelajaran dwibahasa tersebut di sekolah dasar, 2) mendeskripsikan kendala yang dialami guru dalam proses pembelajaran, dan 3) mendeskripsikan harapan para guru mengenai kegiatan pembelajaran dwibahasa tersebut. Populasi penelitian ini adalah guru SD di Bogor. Sampel penelitian 47 guru kelas di enam SD di Bogor. Teknik pengumpulan data melalui kuesioner. Hasil penelitian adalah 1) untuk proses pengajaran: a) bahasa Indonesia dan bahasa Sunda di SD diajarkan oleh guru kelas, b) bahasa pengantar dalam pembelajaran bahasa Sunda tidak menggunakan bahasa tersebut, tetapi menggunakan bahasa Indonesia, c) sarana pembelajaran bahasa di SD kurang memadai dan hanya memiliki buku panduan, dan d) siswa lebih banyak menggunakan bahasa Indonesia dalam proses pembelajaran kedua bahasa itu; 2) kendala yang dihadapi guru adalah a) mereka tidak mendapatkan perhatian yang serius dari sekolah dan pemerintah, dalam upaya peningkatan kemampuan, b) guru yang mengajarkan bahasa Sunda masih kurang keterampilan berbahasa Sunda, dan c) keterampilan berbahasa Sunda guru yang mengajarkan bahasa Sunda masih kurang, khususnya guru yang tidak berbahasa ibu bahasa Sunda, 3) harapan mereka adanya perhatian serius dari pemerintah terhadap pembelajaran bahasa Sunda dan mata pelajaran ini tidak dihapus.
\end{abstract}

Kata kunci: pembelajaran, bahasa, kendala, harapan 


\begin{abstract}
In Indonesia, students are given to learning bilingual languages when they are in elementary school, especially in Bogor, Jawa Barat. They learn Indonesian language and Sundanese language. They learn Sundanese as a foreign language, not as a first language. Bahasa Indonesia is their first language. In temporary, observer of the writer, teaches bilingual languages and makes variety of obstruction. In relation to this, the aim of this research is (1) describing the learning process about learning bilingual languages in elementary school, (2) describing the obstruction that were experienced by teachers in learning process, (3) describing the expectation of teachers in learning bilingual languages. The population of this research was teachers who teach Indonesian language and Sundanese language in 6 elementary schools especially in Bogor. The research sample was 47 teachers. The data are collected by questionnaires. The results are (1) teaching process a) Indonesian and sundanese language are taught by the same teacher who also taught other subject, b) the introduction in learning sundanese doesn't use sundanese, but use Indonesian language, c) learning tools of language learning program in elementary school was not adequate because teachers only have handbook, d) students use more Indonesian language than sundanese in learning process in second language learning. (2) Obstruction toward teacher's experiences are a) they don't have any attention from the institution and goverment to increase their ability, b) teachers who teach undanese don't have skill to speak sundanese well, especially nonnative speaker, c) their expectation is they have any given attention from instituition and goverment to give them training to improve their speaking ability and they want government not to delete sundanese subject from curriculum.
\end{abstract}

Keywords: learning, language, obstruction, and expectation

\title{
I. Pendahuluan
}

\subsection{Latar Belakang}

Saat ini, sehubungan dengan pelestarian bahasa ibu atau daerah, di sekolah dasar sudah diajarkan bahasa ibu atau bahasa daerah dalam mata pelajaran muatan lokal (mulok) tanpa mengabaikan pengajaran bahasa Indonesia. Hal ini sesuai dengan UU Nomor 4 Tahun 2009 tentang Bendera, Bahasa, dan Lambang Negara. Dalam Pasal 29 ayat 1 dinyatakan bahwa Bahasa Indonesia digunakan sebagai bahasa pengantar dalam dunia pendidikan nasional. Di samping menggunakan bahasa Indonesia dalam dunia pendidikan, bahasa daerah dan bahasa asing juga sudah diatur pemakaiannya dalam pendidikan, yakni Pasal 29 ayat 2 dan Pasal 42 ayat 1--3. Pasal 29 ayat 2 berbunyi "Bahasa pengantar sebagaimana dimaksud pada ayat (1) dapat menggunakan bahasa asing untuk tujuan yang mendukung kemampuan berbahasa asing peserta didik. Pasal 42 ayat 1 berbunyi "Pemerintah daerah wajib mengembangkan, membina, dan melindungi bahasa dan sastra daerah agar tetap

14 | Ranah, Volume 3, Nomor 1, Juli 2014 
memenuhi kedudukan dan fungsinya dalam kehidupan bermasyarakat sesuai dengan perkembangan zaman dan agar tetap menjadi bagian dari kekayaan budaya Indonesia". Pengajaran bahasa daerah di pendidikan formal juga sudah diputuskan saat Kongres Internasional IX Bahasa Indonesia pada tahun 2008.

Hal ini pun telah diterapkan di Bogor, Jawa Barat, yakni siswa diberikan mata pelajaran pendidikan dwibahasa: bahasa Indonesia dan bahasa ibu (bahasa Sunda). Pengajaran bahasa Sunda di SD sesuai dengan SK Gubenur Jawa Barat Nomor 423.5/Kep.674-Disdik/2006.

Pemerintah Jawa Barat juga telah menyusun Standar Kompetensi dan Kompetensi Dasar (SKKD) Mata Pelajaran Bahasa dan Sastra Sunda. Penyusunan ini berdasarkan Peraturan Daerah Provinsi Jawa Barat No. 5 Tahun 2003 tentang Pemeliharaan Bahasa, Sastra, dan Aksara Daerah, yang menetapkan bahasa daerah, antara lain, bahasa Sunda, diajarkan di pendidikan dasar di Jawa Barat. Kebijakan tersebut sejalan dengan jiwa UU Nomor 22/1999 tentang Pemerintahan Daerah dan UU Nomor 20/2003 tentang Sistem Pendidikan Nasional, yang bersumber dari UUD 1945 mengenai Pendidikan dan Kebudayaan dan sejalan pula dengan Rekomendasi UNESCO tahun 1999 tentang "Pemeliharaan Bahasabahasa Ibu". Selain itu, kebijakan ini juga sesuai dengan Peraturan Pemerintah Republik Indonesia Nomor 19 Tahun 2005 tentang Standar Nasional Pendidikan. Pada Bab III Pasal 7 ayat 3-8 dinyatakan bahwa dari SD/MI/SDLB, SMP/MTs./SMPLB, SMA/MAN/SMALB, dan SMK/MAK diberikan pengajaran muatan lokal yang relevan. SKKD ini diputuskan oleh Gubernur Jawa Barat.

Berkaitan dengan pembelajaran dwibahasa tersebut, dari hipotesis sementara, penulis menyimpulkan adanya kendala dalam pelaksanaan pengajaran dwibahasa tersebut. Kendala tersebut terutama dari ketersediaan guru SD yang berpendidikan sarjana sastra daerah dan kendala kemampuan berbahasa Sunda guru-guru kelas, terutama yang tidak berbahasa daerah atau bahasa ibunya bukan bahasa Sunda.

Sementara itu, penelitian tentang pembelajaran dwibahasa pernah dilakukan oleh Sofianita (2011) dan Haris (2010). Permasalahan yang ditemukan Sofianita dan Haris berbeda. Sofianita menemukan permasalahan kekurangan sarana dan prasarana, sedangkan Haris menemukan kendala dalam kompetensi guru. Hal ini dapat dilihat dari kesimpulan penelitian mereka sebagai berikut.

Sofianita (2011) menyimpulkan bahwa faktor penghambat implemetasi bilingual di SD di antaranya adalah keterbatasan penyediaan sarana dan prasarana. Haris (2010) menyimpulkan bahwa perlu ada sinergisitas antara kurikulum dengan kompetensi guru dalam bidang bahasa, untuk mencapai tujuan pembelajaran bilingual.

\subsection{Rumusan Masalah}

Berkaitan dengan latar belakang, rumusan masalah dalam penelitian ini ada tiga.

1. Bagaimana proses pembelajaran dwibahasa tersebut di sekolah dasar di Bogor?

2. Apakah kendala yang dialami guru dalam proses pembelajaran?

3. Apa harapan para guru mengenai kegiatan pembelajaran dwibahasa tersebut?

\subsection{Tujuan}

Sesuai dengan rumusan masalah, tujuan penelitian ini juga ada tiga. Ketiga tujuan penelitian ini adalah sebagai berikut:

Ranah, Volume 3, Nomor 1, Juli 2014 | 15 
1) mendeskripsikan proses pembelajaran dwibahasa tersebut di sekolah dasar,

2) mendeskripsikan kendala yang dialami guru dalam proses pembelajaran, dan

3) mendeskripsikan harapan para guru mengenai kegiatan pembelajaran dwibahasa tersebut.

\subsection{Metode}

Penelitian ini merupakan penelitian kualitatif dan kuantitatif. Sifat penelitian adalah deskriptif analisis. Populasi penelitian ini adalah guru SD di Bogor. Sampel penelitian 47 guru kelas di enam SD di Bogor, yakni SDN 01 Babakan Dramaga, Kebon Pedas 1, Muaraberes, Bogor Baru, SDN Polisi 5, dan SDN 02 Pagi Ciluar.

Teknik pengumpulan data melalui kuesioner dan wawancara mendalam. Skala pengukuran yang digunakan dalam kuesioner adalah skala Likert karena skala ini menurut Sugiyono (2006), dapat digunakan untuk mengukur sikap, pendapat, dan persepsi seseorang atau sekelompok orang tentang fenomena sosial.

\subsection{Kerangka Teori}

Pada bagian ini akan dipaparkan tiga teori pembelajaran. Ketiga teori itu adalah pembelajaran bahasa, media pembelajaran, dan hambatan pembelajaran.

\subsubsection{Pembelajaran Bahasa}

Pendidikan multikultural merupakan suatu cara untuk memberikan kesempatan kepada sekolah sebagai bagian dari sistem pendidikan agar dapat mengimplementasikan kegiatan pembelajarannya dengan memadukan unsur lokal dan Indonesia. Menurut Miarso (2004), pembelajaran adalah usaha mengelola lingkungan belajar dengan sengaja agar seseorang membentuk diri secara positif dalam kondisi tertentu, sedangkan pengajaran untuk membimbing dan mengarahkan pengalaman belajar kepada peserta didik yang biasanya berlangsung dalam situasi formal atau resmi. Jadi, ditegaskan oleh Miarso (2004) bahwa pembelajaran adalah usaha yang dilakukan untuk membuat pembelajar mengalami proses belajar.

Pembelajaran adalah menguasai atau memperoleh dengan cara mengingatingat informasi atau keterampilan dengan melibatkan sistem penyimpanan, memori, dan organisasi kognitif, serta berperan aktif berdasarkan peristiwa yang dialaminya dengan latihan yang ditopang dengan imbalan dan hukuman. Penguasaan ini bersifat permanen (menetap) sehingga menghasilkan perubahan dalam perilaku (Brown, 2008). Pembelajaran bukan menitikberatkan pada sesuatu yang dipelajari melainkan cara-cara yang dilakukan untuk mencapai tujuan yang berkaitan dengan cara pengorganisasian materi dan cara penyampaian dengan hasil akhir perubahan yang diinginkan pada perilaku pembelajar.

Sementara itu, di dalam proses pembelajaran bahasa menurut Kushartanti et al.(2007), dikenal istilah hipotesis umur kritis (critical age hypothesis) yang mempertimbangkan usia sebagai faktor untuk mencapai kemampuan berbahasa. Mereka mengutip Lenneberg (1967) dan Krashen (1972). Lenneberg menyatakan bahwa usia 2 sampai dengan 12 tahun merupakan usia yang sangat ideal untuk mencapai kemampuan berbahasa seperti penutur asli, sedangkan menurut Krashen 
usia yang ideal untuk belajar bahasa adalah di bawah lima tahun.

\subsubsection{Media Pengajaran}

Untuk mendorong siswa membangun pengetahuannya sendiri, siswa perlu dibiasakan untuk memecahkan masalah, menemukan sesuatu yang berguna bagi dirinya, dan bergelut dengan ide-ide. Hal itu diungkapkan Trianto (2009) mengutip Downey (1967) yang menyatakannya sebagai berikut.

The core of good thinking is the ability to solve problems. The essence of problem solving is the ability to learn in puzzling situations. Thus, in the school of these particular dreams, learning how to learn pervades what is taught, how it is taught, and the kind of place in which it is taught.

Bagi guru, bertanya adalah kegiatan untuk mendorong, membimbing, dan menilai kemampuan berpikir siswa. Bagi siswa, kegiatan bertanya merupakan bagian penting dalam melaksanakan pembelajaran, yaitu menggali informasi, mengonfirmasikan sesuatu yang telah diketahui, dan mengarahkan pada aspek yang belum diketahuinya. Untuk mengembangkan keterampilan siswa diperlukan media sebagai bagian dari kegiatan pembelajaran. Dalam Kamus Besar Bahasa Indonesia (2008), pengertian media berarti alat atau sarana. Kata media berasal dari bahasa Latin dan merupakan bentuk jamak dari medium yang secara harfiah berarti perantara atau pengantar pesan dari pengirim ke penerima pesan. Pateda (1995) mengatakan bahwa diperlukan pengorbanan guru untuk membeli alat bantu mengajar yang dibutuhkan dan ada kriteria pemahahaman bahan sebaiknya dikuasai.

\subsubsection{Hambatan dan Tantangan Pembelajaran}

Faktor penentu dalam pembelajaran bahasa kedua menurut Chaer ( 2003) ada lima: 1) motivasi, 2) usia, 3) penyajian formal, 4) bahasa pertama, dan 5) lingungan. Motivasi yang dimaksudkan adalah orang yang di dalam dirinya ada keinginan, dorongan atau tujuan yang ingin dicapai dalam belajar bahasa kedua cenderung akan lebih berhasil dibandingkan yang tidak. Selanjutnya, dari segi usia, anak-anak jauh lebih berhasil dalam pembelajaran bahasa kedua dibandingkan dengan orang dewasa (Djunaidi, 1990; dalam Chaer, 2003). Dulay (1982; dalam Chaer, 2003) mengatakan bahwa lingkungan kelas merupakan lingkungan yang memfokuskan pada kesadaran dalam pemerolehan kaidah-kaidah dan bentuk-bentuk bahasa yang dipelajari. Steiberg (1976) yang dikutip Chaer (2003) juga mengungkapkan bahwa ada lima karekteristik lingkungan di kelas, yakni 1 ) diwarnai faktor psikologi sosial yang meliputi penyesuai, disiplin, dan prosedur; 2) dilakukan praseleksi terhadap data linguistik berdasarkan kuirkulum; 3) disajikan kaidah-kaidah gramatikal; 4) disajikan data dan situasi bahasa buatan; 5) disediakan alat-alat pengajaran, seperti buku teks, buku penunjang, dan tugas-tugas.

Faktor bahasa pertama menurut Ellis (1986) yang dikutip Chaer (2003) adalah bahasa pertama lebih mempunyai pengaruh terhadap proses penguasaan bahasa kedua pembelajar. Begitu pun dengan faktor lingkungan, menurut Tjohjono (1990; dalam Chaer, 2003), lingkungan bahasa hal yang didengar dan dilihat oleh pembelajar, seperti situasi restoran atau toko. Lebih lanjut Krashen (1981; dalam 
Chaer, 2003) mengatakan bahwa lingkungan bahasa dibedakan formal seperti di kelas dalam proses belajar mengajar dan informal (natural atau alamiah)

Menurut Pateda (1995), ada tiga belas kendala dalam pengajaran bahasa. Kendala tersebut khususnya dalam pengajaran kosakata, yakni 1) peserta didik malumalu, tidak berani berkata-kata, ia diam, bahkan kadang-kadang takut; 2) bahan yang diajarkan belum pernah didengar peserta dididik sehingga kata itu betul-betul asing baginya; 3) sikap guru mata pelajaran lain yang tidak mendukung upaya guru bahasa; 4) lingkungan hidup peserta dididik yang tidak mendukung, misalnya penduduk tidak menggunakan bahasa Indonesia; 5) peserta didik sama sekali tidak mengetahui bahasa Indonesia, dengan kata lain, peserta didik hanya menguasai bahasa ibunya; 6) alat peraga yang dapat dimanfaatkan tidak ada; 7) guru kesulitan menggambarkan isi kata yang akan diajarkan; 8) peserta didik lama sekali mereaksi sehingga kemungkinan bahan yang dipersiapkan tidak akan selesai; 9) tingkat kepandaian dan daya serap peserta didik yang berbeda-beda, yakni orang yang pandai akan terus memonopoli tugas yang diberikan guru, sedangkan peserta didik yang bermasalah dalam pelajaran akan terus diam; 10) peserta didik tidak memahami hal yang dikatakan guru, dengan kata lain, kosakata peserta didik terbatas sekali; 11) alat bantu yang sulit diperoleh; 12) kendala yang berhubungan dengan pengelolaan kelas, misalnya peserta didik yang suka menggangu temannya, kebisingan, dan gangguan dari luar; 13) daya bayang peserta didik yang terbatas.

\section{Hasil dan Pembahasan}

Pada bagian pembahasan ini, akan dipaparkan tiga hal sesuai dengan tujuan penelitian. Ketiga hal yang akan dipaparkan adalah sebagai berikut: 1) proses pembelajaran dwibahasa tersebut di sekolah dasar, 2) mendeskripsikan kendala yang dialami guru dalam proses pembelajaran, dan 3) mendeskripsikan harapan para guru mengenai kegiatan pembelajaran dwibahasa tersebut.

\subsection{Proses Pembelajaran Dwibahasa di Sekolah Dasar}

Pada bagian ini akan dipaparkan proses pembelajaran dwibahasa. Proses pembelajaran dwibahasa itu adalah pembelajaran bahasa Sunda dan bahasa Indonesia.

\subsubsection{Proses Pembelajaran Bahasa Sunda}

Dari hasil penilitian, dapat diketahui bahwa guru tidak selalu menggunakan bahasa Sunda sebagai bahasa pengantar dalam mata pelajaran bahasa Sunda (MPBS), yakni hanya 11 responden guru kelas (24\%) yang menyatakan selalu (menggunakan 
bahasa Sunda sebagai bahasa pengantar) dari 47 responden guru kelas. Persentase guru yang menyatakan selalu menggunakan bahasa Sunda adalah pada waktu menjawab pertanyaan siswa. Hal ini dinyatakan oleh $34 \%$ responden. Sebanyak $44,7 \%$ responden guru menyatakan bahwa sering menggunakan bahasa Sunda untuk bertanya kepada siswa dan hanya $23,4 \%$ responden menyatakan selalu. Sementara itu, hanya $12,8 \%$ responden guru menyatakan selalu menggunakan bahasa Sunda untuk menegur siswa dan 31,9\% responden menyatakan selalu memperbaiki bahasa Sunda yang dituturkan siswa. Oleh karena itu, pemakaian bahasa Sunda dalam kegiatan pembelajaran bahasa Sunda masih rendah (lihat Tabel 1).

TABEL 1

PERSENTASE PEMAKAIAN BAHASA SUNDA

PADA MATA PELAJARAN BAHASA SUNDA OLEH GURU

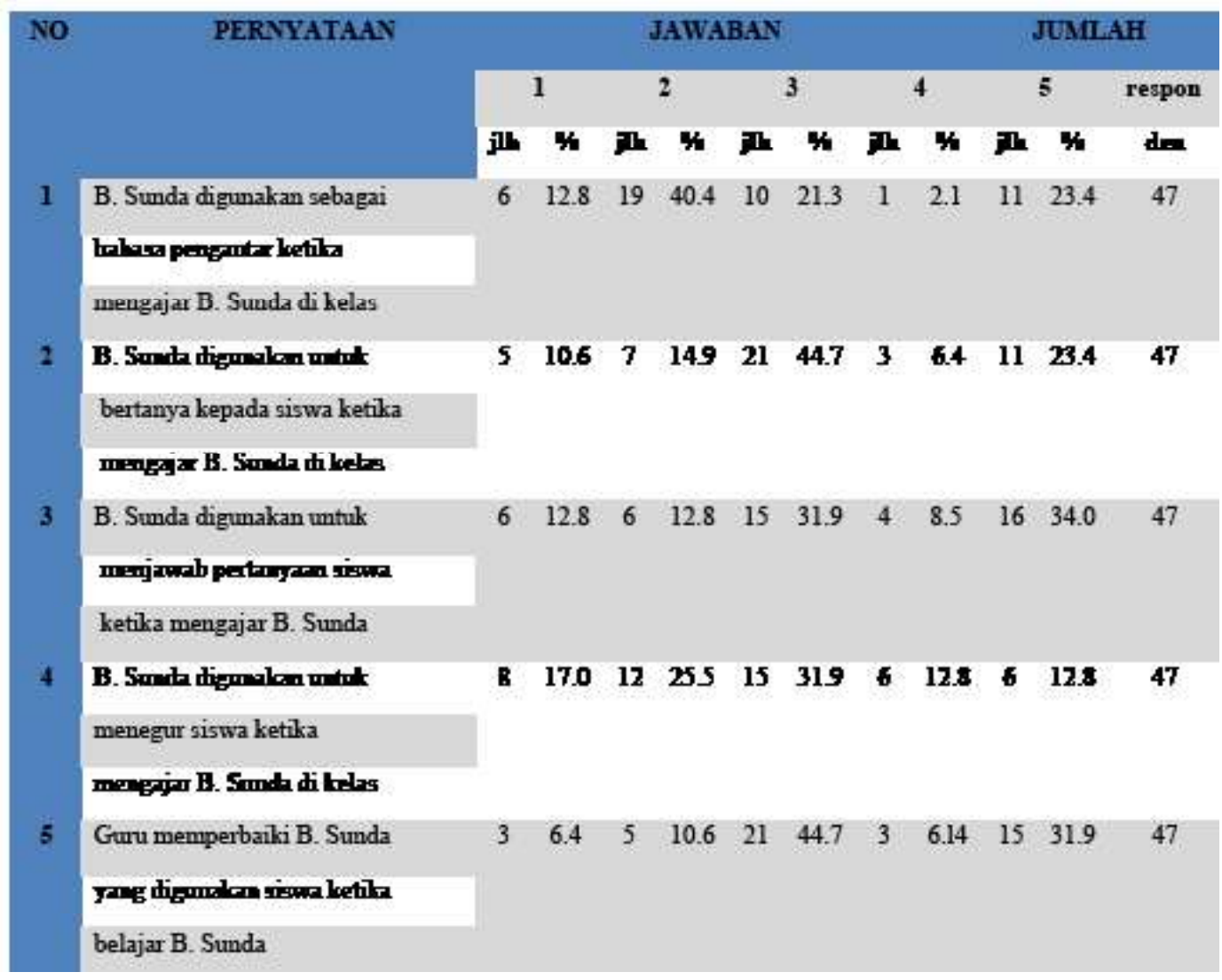

Ctt: 1=tidak pernah; 2 =jarang; $3=$ sering; $4=$ sangat sering; $5=$ selalu

Selanjutnya, pemakaian bahasa Sunda oleh responden guru kelas pada saat mengajar pada mata pelajaran lain (MPL) memiliki persentase yang sangat rendah. Dari 47 responden, ada 65,9\% yang menyatakan tidak pernah menggunakan bahasa Sunda sebagai bahasa pengantar. Begitu pula untuk bertanya dan menjawab pertanyaan siswa $61,7 \%$ dan $70,2 \%$ responden menyatakan tidak pernah menggunakan bahasa Sunda. Sementara itu, 55,3\% responden guru menyatakan jarang dan 4,3\% menyatakan sering serta $2,1 \%$ menyatakan sangat sering menggunakan bahasa 
Sunda untuk menegur siswa. Untuk menegur perlu adanya kedekatan emosi sehingga bahasa Sunda dianggap bahasa yang mewakili kedekatan tersebut, tanpa adanya jarak antara guru dan siswa. Karena itu, hanya 38,3\% yang menyatakan tidak pernah menggunakan bahasa Sunda untuk menegur siswa.

TABEL 2

\section{JUMLAH DAN PERSENTASE PEMAKAIAN BAHASA SUNDA PADA MATA PELAJARAN LAIN}

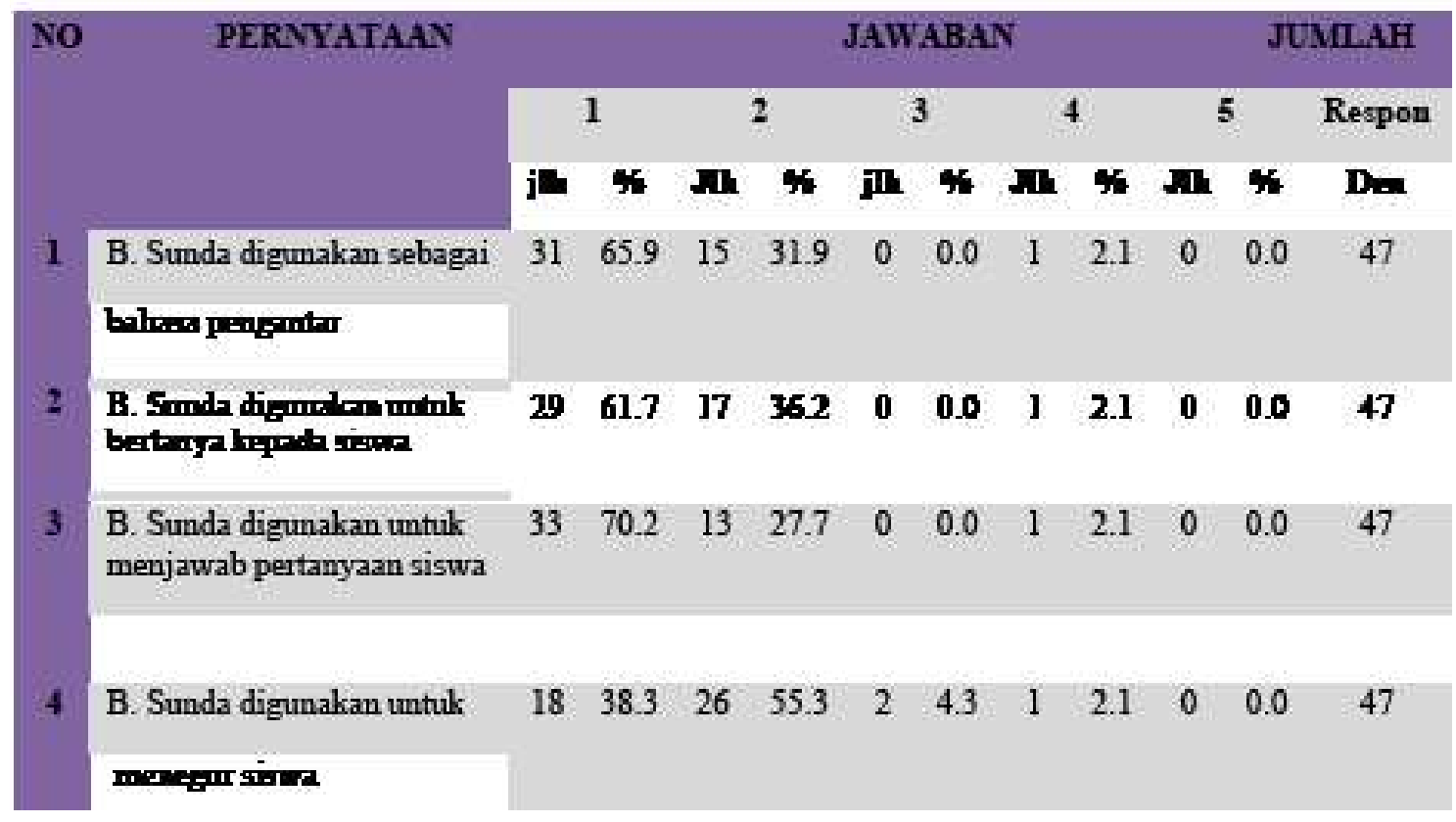

Ctt: $1=$ tidak pernah; 2 =jarang; $3=$ sering; $4=$ sangat sering; $5=$ selalu; $0=$ tidak menjawab

Tingkat antusiasme siswa terhadap pembelajaran bahasa Sunda rendah. Hal ini dapat diketahui bahwa hanya $8,5 \%$ responden guru menyatakan bahwa siswa bertanya kepada guru di kelas bahasa Sunda. Begitu pula dengan tingkat pemakaian bahasa Sunda oleh siswa di Bogor, berdasarkan pernyataan responden guru, hal itu sangat rendah. Perlu adanya perbaikan pembelajaran bahasa Sunda supaya siswa lebih aktif karena berdasarkan persentase pemakaian bahasa Sunda siswa pada mata pelajaran bahasa Sunda maupun pada mata pelajaran lain, tidak ada satupun responden guru yang menyatakan bahwa siswa mereka memakai bahasa Sunda ketika bertanya. Dengan bertanya, hal ini menunjukkan keaktifan siswa di kelas. Namun begitu, $12,8 \%$ responden guru menyatakan bahwa siswa mereka menjawab dengan bahasa Sunda ketika pembelajaran bahasa Sunda dan 2,1\% responden guru juga menyatakan bahwa siswa menjawab dengan bahasa Sunda ketika pembelajaran mata pelajaran lain. 
Dalam berinteraksi dengan teman-teman di sekolah, siswa mempunyai kecenderunganmenggunakan bahasaSunda. Ada 4,3\% respondenguruyangmenyatakan bahwa siswa selalu menggunakan bahasa Sunda jika berinteraksi di sekolah, ada 14,9\% responden menyatakan bahwa siswa sangat sering, dan $12,8 \%$ responden menyatakan sering (lihat Tabel 3). Artinya, siswa yang tidak pernah menggunakan bahasa Sunda saat berinteraksi dengan teman-temannya sedikit. Ada 25,5\% responden guru yang menyatakan bahwa siswa tidak pernah menggunakannya.

\section{TABEL 3}

\section{JUMLAH DAN PRESENTASE PEMAKAIAN B. SUNDA PADA MPBS DAN MPL OLEH SISWA}

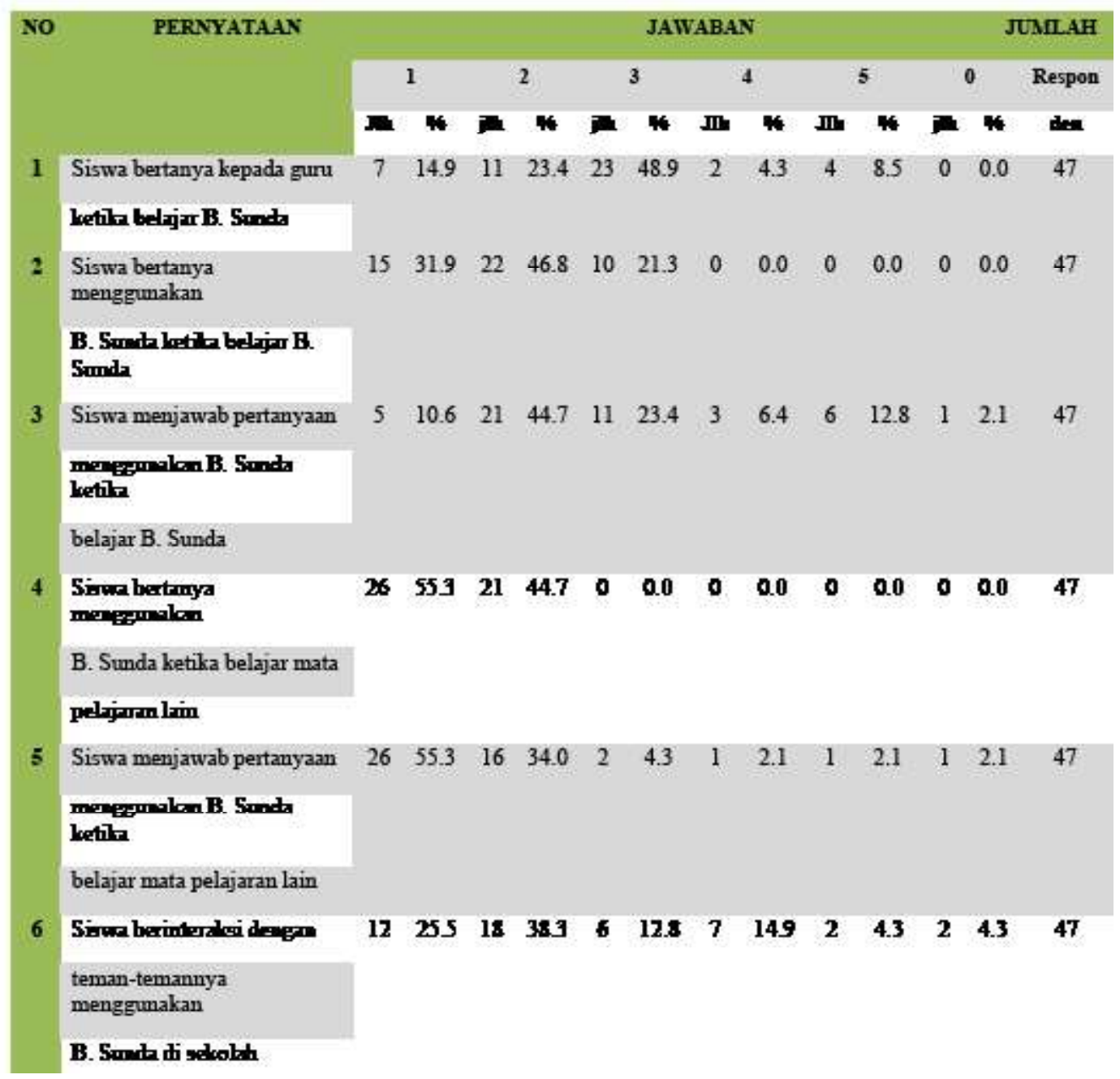

Ctt: 1 =tidak pernah; $2=$ =jarang; $3=$ sering; $4=$ sangat sering; 5 =selalu; $0=$ tidak menjawab

\subsubsection{Proses Pembelajaran Bahasa Indonesia}

Pemakaian bahasa Indonesia oleh guru pada saat mengajarkan mata pelajaran Bahasa Indonesia (MPBI) sangat sering. Bahkan, persentasenya sangat tinggi untuk pernyataan selalu menggunakan bahasa Indonesia (87,2\%), yakni sebagai bahasa pengantar, saat bertanya, menjawab pertanyaan, dan menegur siswa.

Akan tetapi, pemakaian bahasa Indonesia oleh guru pada saat mengajarkan mata pelajaran Bahasa Indonesia (MPBI) lebih sering jika dibandingkan dengan pada 
saat mengajar mata pelajaran lain (MPL). Hal ini dapat terjadi karena guru menyelipkan bahasa Sunda dalam kegiatan pembelajaran mata pelajaran lain. Sementara itu, ketika guru mengajar mata pelajaran bahasa Indonesia, mereka lebih konsisten untuk tetap menggunakan bahasa Indonesia. Responden guru yang menyatakan selalu menggunakan bahasa Indonesia pada saat mengajar MPBI sebanyak $87,2 \%$. Persentase yang sama juga terdapat pada pernyataan responden guru ketika bertanya, menjawab, dan menegur siswa. Responden selalu menggunakan bahasa Indonesia sebagai pengantar pada MPL $(74,5 \%)$, bertanya (77\%), menjawab (79\%), dan menegur $(77,0 \%)$ (lihat Tabel 4$)$.

TABEL 4

\section{PERSENTASE PEMAKAIAN BAHASA INDONESIA PADA MPBI DAN MPL OLEH GURU}

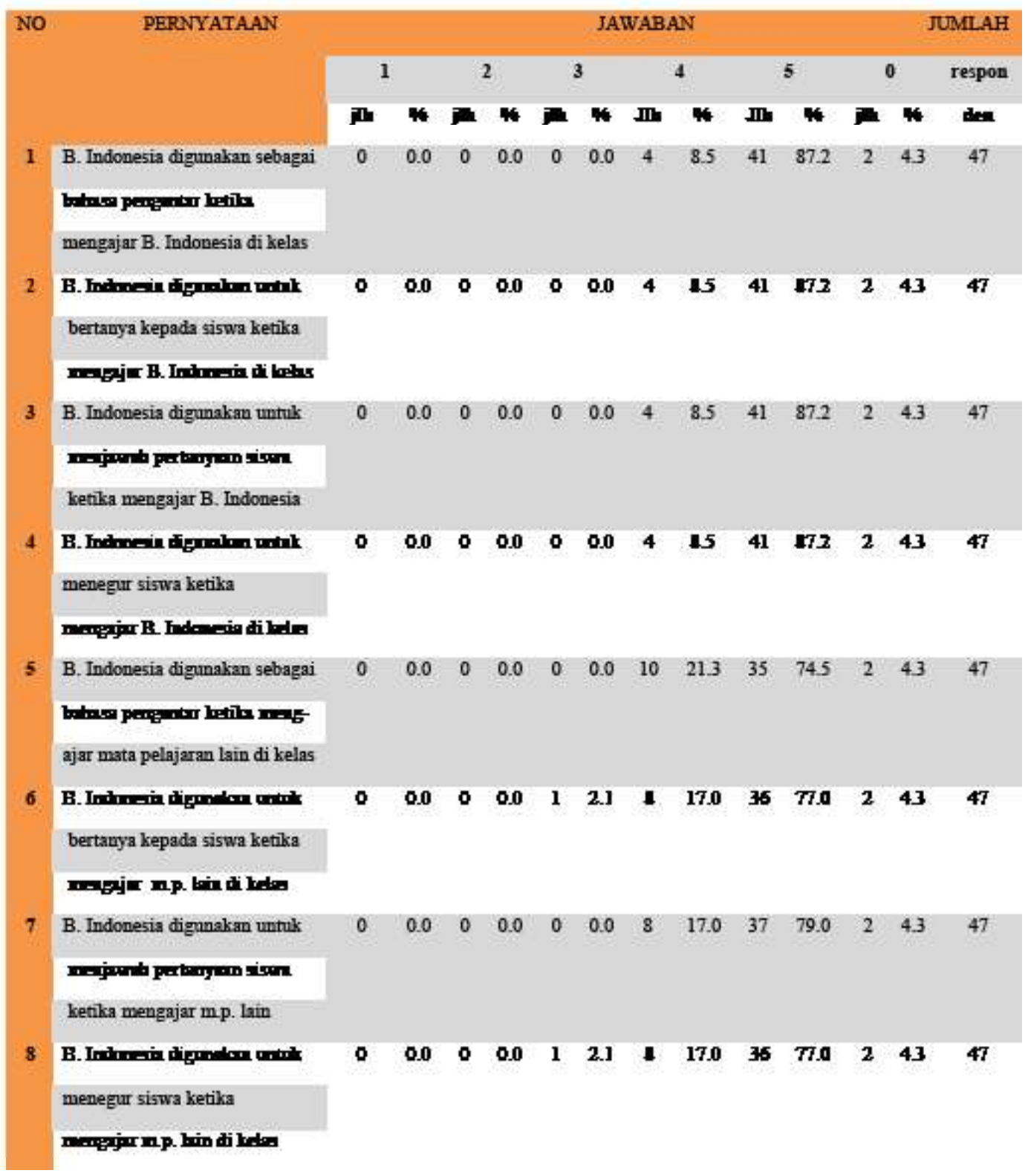

Ctt: $1=$ tidak pernah; $2=$ jarang; 3 =sering; $4=$ sangat sering; $5=$ selalu; $0=$ tidak menjawab 
Persentase pemakaian bahasa Indonesia pada saat MPBI oleh siswa lebih rendah jika dibandingkan dengan guru, yakni kurang dari $80 \%$. Menurut guru, siswa yang selalu menggunakan bahasa Indonesia pada saat MPBI lebih tinggi pada saat menjawab daripada saat bertanya, yakni $74,5 \%$ saat menjawab dan $61,7 \%$ saat bertanya.

Jika dibandingkan dengan persentase pemakaian bahasa Indonesia oleh siswa pada saat MPBI dengan MPL, pemakaian bahasa Indonesia lebih tinggi pada saat MPL. Siswa selalu menggunakan bahasa Indonesia saat MTP adalah $76,6 \%$ saat bertanya dan $74,5 \%$ saat menjawab (lihat Tabel 5).

Dengan demikian, dari Tabel 5 dapat disimpulkan dua hal. Pertama, siswa tidak pernah tidak menggunakan bahasa Indonesia dalam proses belajar mengajar, baik pada saat mata pelajaran bahasa Indonesia maupun pada saat mata pelajaran lain. Kedua, masih ada guru yang tidak pernah memperbaiki kesalahan berbahasa Indonesia siswanya $(4,3 \%)$

TABEL 5

\section{PERSENTASE PEMAKAIAN BAHASA INDONESIA OLEH SISWA DALAM PROSES BELAJAR}

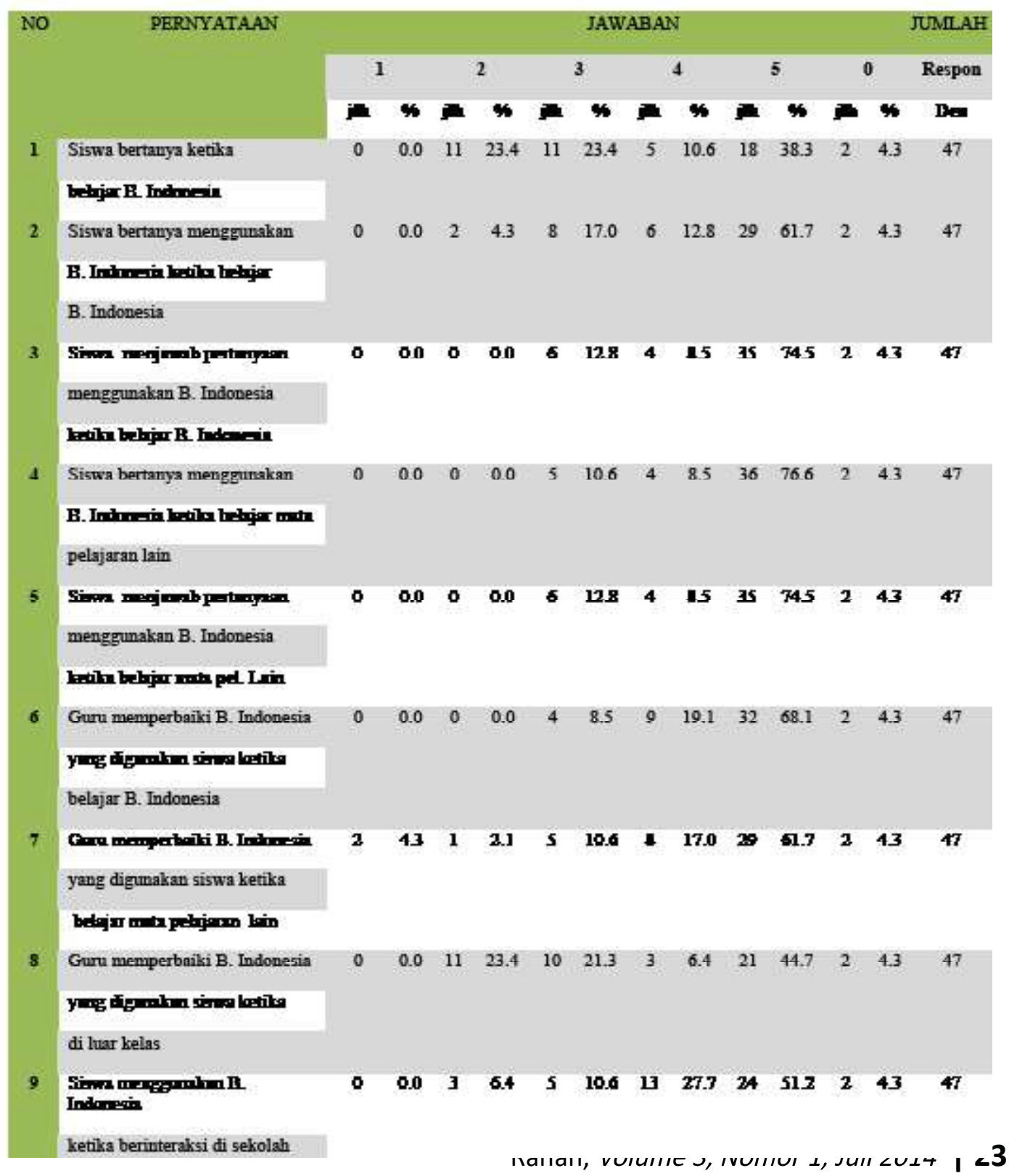


Ctt: 1=tidak pernah; 2=jarang; $3=$ sering; $4=$ sangat sering; $5=$ selalu; $0=$ tidak menjawab

\subsection{Kendala dan Harapan dalam Pembelajaran Dwibahasa}

Berdasarkan teori yang dikemukan Pateda (1995) dan Chaer (2003) tentang kendala pengajaran bahasa, kendala utama yang dialami guru adalah tidak lengkapnya bahan ajar dan alat peraga. Untuk pelajaran Bahasa Sunda, guru tidak memiliki alat peraga. Sementara itu, untuk mata pelajaran Bahasa Indonesia, guru sudah memiliki dan menggunakan alat peraga, yakni yang menyatakan sangat sering $74,5 \%$. Selanjutnya, buku pegangan guru untuk mata pelajaran Bahasa Indonesia masih kurang, yakni 72,3\% guru yang menyatakan sudah mencukupi. Bahkan, persentase ini lebih rendah lagi untuk buku pegagangan siswa, yakni $66 \%$ responden menyatakan sudah cukup.

Selain kendala bahan ajar dan alat peraga, kendala yang ditemukan berdasarkan pengakuan guru adalah kemampuan berbahasa Sunda guru, yakni masih ada guru kelas yang belum bisa berbahasa Sunda. Alasannya, mereka bukan orang Sunda sedangkan pelatihan untuk itu masih kurang.

Selama ini, mereka menilai bahwa baik kepala sekolah maupun dinas pendidikan sangat jarang menyelenggarakan atau mengutus mereka untuk mengikuti pelatihan guru kelas. Sementara itu, sebagai guru kelas, mereka harus menguasai semua mata pelajaran (kecuali agama, bahasa Inggris, dan olahraga seni).

\section{Penutup}

\subsection{Kesimpulan}

Sesuai dengan tujuan penulisan, kesimpulan dalam penulisan ini juga ada tiga. Ketiga kesimpulan itu adalah sebagai berikut.

1. Untuk proses pengajaran: a) bahasa Indonesia dan bahasa Sunda di SD diajarkan oleh guru kelas, b) bahasa pengantar dalam pembelajaran bahasa Sunda dan Indonesia menggunakan bahasa Indonesia, c) sarana pembelajaran bahasa di SD kurang memadai dan hanya memiliki buku panduan, d) siswa lebih banyak menggunakan bahasa Indonesia dalam proses pembelajaran dwibahasa itu.

2. Kendala yang dihadapi guru adalah a) mereka tidak mendapatkan perhatian yang serius dari sekolah dan pemerintah, dalam upaya peningkatan kemampuan, b) guru yang mengajarkan bahasa Sunda masih kurang keterampilan berbahasa Sunda.

3. Harapan para guru yang menjadi responden pada penelitian ini adalah adanya perhatian serius dari pemerintah terhadap pembelajaran bahasa Sunda dan mata pelajaran ini tidak dihapus dari kurikulum.

\subsection{Saran}

Berdasarkan hasil penelitian, saran yang dapat diberikan adalah sebagi berikut.

1. Sarana pembelajaran bahasa di SD yang masih kurang memadai dan hanya memiliki buku panduan, perlu ditingkatkan dengan penambahan buku ajar terutama buku 
pegangan guru serta ada alat peraga, seperti video, dan gambar-gambar.

2. Kurangnya perhatian sekolah dan pemerintah, dalam upaya peningkatan kemampuan kelas yang tidak hanya mengajar mata pelajaran lain, tetapi juga mengajar bahasa Indonesia dan bahasa Sunda, dapat diatasi dengan cara semakin sering diadakan pertemuan guru di tingkat kecamatan, khususnya membahas permasalahan yang dihadapi dalam mengajar mata pelajaran bahasa Indonesia dan bahasa Sunda.

3. Permasalahan guru yang mengajarkan bahasa Sunda masih kurang keterampilan berbahasa Sunda perlu dilatih lagi. Bahkan, pemerintah daerah dapat memberdayakan sarjana sastra daerah (bahasa dan sastra Sunda) dalam membantu pelestarian bahasa Sunda.

* Ucapan Terima kasih kami sampaikan kepada mitra bebestari atas penyuntingan tulisan ini sehingga tulisan ini dapat layak muat.

\section{Daftara Pustaka}

Badan Pengembangan dan Pembinaan Bahasa Kementerian Pendidikan dan Kebudayaan]. 2011. Undang-Undang Republik Indonesia Nomor 4 Tahun 2009 tentang Bendera, Bahasa, dan Lambang Negara serta Lagu Kebangsaan. Jakarta.

Brown, H Douglas.2008. Prinsip Pembelajaran dan Pengajaran Bahasa. Cholis Noor, Avianto Y, penerj. Jakarta (ID): Kedubes AS. Terjemahan dari The Principles of Language Teaching and Learning.

Chaer, Abdul. 2003. Psikolinguistik Kajian Teoritis. Jakarta (ID): Rineka Cipta.

Depdiknas Departemen Pendidikan Nasional. 2008. Kamus Besar Bahasa Indonesia. Edisi IV. Jakarta (ID): Gramedia.

Disdikjabar. Dinas Pendidikan Provinsi Jawa Barat. 2006. Standar Kompetensi Mata Pelajaran Bahasa dan Sastra Sunda. Bandung: Disdik. Web. disdik. jabarprov.go.id [internet]. [2014 Jun 26].

Kushartanti, Yuwono, U dan Lauder, Multamia RMT, Ed.2007. Pesona Bahasa: Langkah Awal Memahami Linguistik. Jakarta (ID): Gramedia.

Haris, Imram W. 2010. Model Pengajaran Bilingual pada Anak Usia Dini pada SD Anak Saleh Sidoarjo." Pamator. 3( 2): 186-190.

http://Ippm.trunojoyo.ac.id/upload/penelitian/penerbitan_jurnal/10_ pamator\%20V01\%203\%20No\%202\%200tober\%202010.pdf _[internet]. [2014 Jun 26].

Miarso, Yusufhadi. 2004. Menyemai Benih Teknologi Pendidikan. Jakarta (ID):Prenada.

Pateda, Mansur. 1995. Kosakata dan Pengajarannya. Cet. I. Flores (ID): Nusa Indah.

Sofianita, Dian. 2011. Implementasi Penggunaan Bilingual (Studi kasus di SD Plus Qurrota A'yun Malang) [tesis]. Malang (ID): UIN Maulana Malik Ibrahim. http://lib.uin-malang.ac.id/?mod=th_viewer\&id=abstract/id_09760002.pdf [internet].[2014 Jun 26].

Trianto. 2009. Mendisain Model Pembelajaran Inovatif dan Progresif. Jakarta (ID): Prenada Media. 